\title{
Urban Groundwater Management Issues in Sri Lanka
}

\author{
Gemunu Herath and Uditha Ratnayake
}

Abstract: The demand for ground water in Sri Lanka has grown rapidly over the past few decades, mainly as a result of population growth, economic development, and shortages of rainfall. Recent estimate show that over 55 percent of the population now relies on groundwater for their domestic water requirements. As a free and easily tapped commodity, groundwater today is utilized in a wide variety of uses. In some parts of the country including many locations in Kandy and Colombo, high pumping rates have lowered the groundwater table, causing the wells to go dry and affecting the natural water courses including those used for drinking. If these situations get worse, water shortages could become severe, especially during the more frequent extended dry spells being experienced, possibly due to climatic changes. Further, water pollution from domestic, agricultural and industrial sources is contaminating the surface water and groundwater and affecting the environment and further placing more pressure on the available water resources. Therefore this paper identifies several critical issues as urgent challenges to be immediately addressed and proposes policy recommendations to achieve sustainable groundwater resources in Sri Lanka.

Keywords: Groundwater, Hydrogeology, Land use, Management policy, Sri Lanka, Water pollution

\section{Introduction}

The "EarthTrends" countryprofile on Sri Lanka (2003) estimates the total renewable water resources available within the freshwater ecosystems of Sri Lanka as $49 \mathrm{~km} 3$ surface water, $8 \mathrm{~km} 3$ groundwater and a further $7 \mathrm{~km} 3$ as overlap water making a total internal renewable water resource of about $55 \mathrm{~km} 3$ a year. This is received mainly from the annual rainfall (volume of $120 \mathrm{~km} 3$ ) of which more than $50 \%$ is lost through evapotranspiration and a further $20 \%$ infiltrate down to replenish the groundwater leaving only about $30 \%$, or about $35 \mathrm{~km} 3$ available as surface runoff. This estimated internal renewable water determines the available per capita freshwater volume as $2,900 \mathrm{~m} 3$ for the population of 2001. Though Sri Lanka is blessed with good water resources when one considers the total aggregate water availability, the variations over space and time, from the historical perspective, demand a proper management strategy.

In terms of the amount and pattern of the rainfall received, Sri Lanka can be divided mainly into three different climatic zones. These zones are referred to as wet zone, intermediate zone and dry zone. The average annual rainfall varies from $1,000 \mathrm{~mm}$ in some parts of the dry zone to over $5,000 \mathrm{~mm}$ in parts of the wet zone. This precipitation is brought mostly from and inter-monsoons and inter-monsoons. However with recent climatic changes experiencing, the average rainfall iso-lines from

1911 to 1940 , compared with the average rainfall iso-lines from 1961 to 1990 show that the rainfall has significantly reduced all over the country, specially around Kandy (Ratnayake and Herath 2005). Further it is revealed that the lengths of dry periods have increased all over the country and the lengths of wet periods have decreased. These irregularities and uncertainties in rainfall together with the increasing demands of population growth have made the competition and water shortages to increase in Sri Lanka. In addition pressure from population growth is causing degradation of watersheds, resulting in soil erosion, sedimentation of reservoirs, landslides and more serious floods and droughts further limiting the available resources.

As a result demand for groundwater is increasing throughout the country specially in urban and agricultural regions raising doubts on its sustainability in the longer run. Water pollution from domestic, agricultural and industrial sources is contaminating the surface

Dr. Gemunu Herath, Senior Lecturer, Department of Civil Engineering, Faculty of Engineering, University ofPeradeniya, Obtained the B.Sc. Engineering (in Civil Engineering) fromPeradeniya, M.Engg., from AIT, Thailand and PhD., From University of Tokyo Japan.

Eng. (Dr.) Uditha Ratnayake, Senior Lecturer, Department of Civil Engineering, Faculty ofEngineering, University of Peradeniya, Obtained the BSC Engineering (in Civil Engineering) from Peradeniya, M.Engg. and PhD from AIT, Thailand. 
water and groundwater affecting the environment and public health has further aggravated the problem. These concerns have demanded immediate counter measures and strategies for proper management of the available water resources in the country.

To assess the current status, a study was initiated mainly focusing the groundwater management practices in two urban centers. The selected study areas are; urban water supply from groundwater in Colombo and Kandy. The Colombo study area includes twenty divisional secretariat divisions while the Kandy study area is limited to only five divisional secretariat divisions (figure 1 ).

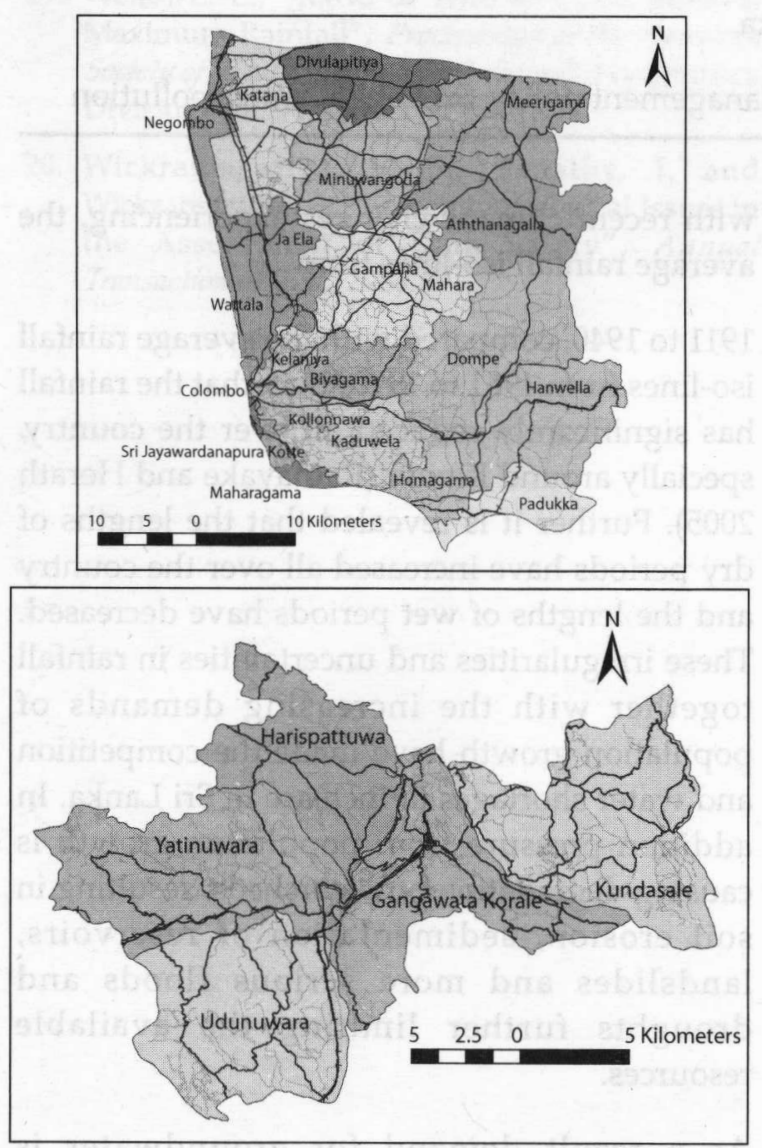

Figure 1: Colombo and Kandy study area extents

Of the two urban areas, Colombo is a coastal city of the western region where its terrain is of gently undulating plains with high density of drainage paths. On the other hand, the Kandy city is a plateau in the central mountains around 500 to 700 meters above sea level. The terrain in Kandy city area does not contain many steep, plunging slopes except in the surrounding mountains. The topography in this plateau consists of undulating plains with hillocks formed by drainage paths separating them.

Both the selected urban areas are located in the wet zone, which receive an average annual rainfall of about $2,000 \mathrm{~mm}$. According to the historical rainfall data, the Colombo study area receives an average annual rainfall of $2376 \mathrm{~mm}$ (40-year average) while the Kandy study area, receives an average of $1841 \mathrm{~mm}$ (60-year average).

\section{Groundwater Resource}

Hydrogeological setting: There are six main types of groundwater aquifers demarcated and identified in Sri Lanka. They are shallow karstic aquifers, coastal sand aquifers, deep confined aquifers, lateritic (cabook) aquifers, alluvial aquifers and shallow regolith aquifers in the hard rock region (Panabokke 2003). In addition to these major aquifers, a large number of small groundwater pockets can be found throughout the country. These aquifers occur in either isolated patches of soil cover over the bedrock or in the fracture and weathered zones of the underlying metamorphic bedrock formation.

Colombo basin hydrology indicates that there is a fair amount of groundwater potential both in the alluvial aquifers and bedrock. The prominent aquifer bedrock types in the basin are quartzite and a few crystalline limestone (marble) bands. Though over $90 \%$ of the entire non-coastal area lie on metamorphic hard rock formation, there exists a weathered water bearing rock formation over the hard rock that accommodates a fair amount of groundwater resources. This formation having secondary porosity provides excellent conditions for deep aquifers. The alluvial sand/gravel aquifers in the basin are recharged by rainfall and seepage from the rivers. Due to laterite formation the northwestern region is rich in this resource. High-potential porous residual laterites also contribute to groundwater supplies. During droughts, river water and springs recharge most alluvial aquifers in the basin.

Groundwater in Kandy exists mostly in the form of semi-confined aquifers in the first 100 meters of the bedrock. Groundwater storage exits as small pockets of underground reservoirs or as fissure groundwater. The available amount of water in these aquifers is not very well known 
and is limited as the recharging of these aquifers is very slow. In addition, there exists high-yield groundwater resources along the alluvial flood plains of the Mahaweli River and are mostly recharged by the river water.

\section{Groundwater Issues}

Land use: The land coverage in Colombo and Kandy selected urban areas are $1575.6 \mathrm{~km} 2$ and $322 \mathrm{~km} 2$ respectively. The main land use change during 1987 to 1998 period in both areas is tabulated in table 1 below.

According to these land use data, the main land use change observed in both the study areas is the rapid increase in built-up areas. Colombo shows an increase of over $900 \%$ within the eleven years from 1987 to 1998 . This increase replaces the domestic gardens, water bodies and marshes (a typical domestic garden in Sri Lanka mainly consists of mixed vegetation that surrounds the house). Also there is a significant decline in the extent of domestic gardens, mainly because of migration to commercial crops. Another, significant change in relation to this study is in the reduction of cropping intensity and cultivation area of paddy fields which cover nearly $20 \%$ of the area. This change is happening in both study areas and is not clearly reflected in the land use maps. Paddy cultivation in the late seventies compared to the last decade, has dropped and this has substantially restricted the amount of irrigation water in the paddy fields, thereby reducing the sub-surface flow and recharge, which in turn influenced the groundwater resources in the regions.

Groundwater demand; The water demand in Sri Lanka is steadily increasing particularly for urban and rural water supplies, irrigated agriculture and in the industrial sector. This rapid increase in demand is exerting considerable pressure on the available groundwater resources. According to the WHO/ UNICEF report on "Joint Monitoring Program for Water Supply and Sanitation-2000", only $76.1 \%$ of urban population was supplied with a piped supply compared to $11.4 \%$ in rural areas, while the urban and rural population using underground well-water was estimated to be $22.4 \%$ and $71.8 \%$ respectively. (urban and rural

Table 1: Land use change in Colombo and Kandy

\begin{tabular}{|l|l|l|l|l|l|l|}
\hline \multirow{2}{*}{ Land-Use Type $\left(\mathbf{k m}^{2}\right)$} & \multicolumn{3}{c|}{ Colombo } & \multicolumn{3}{c|}{ Kandy } \\
\cline { 2 - 7 } & $\mathbf{1 9 8 7}$ & $\mathbf{1 9 9 8}$ & \% Change & $\mathbf{1 9 8 8}$ & $\mathbf{1 9 9 6}$ & \% Change \\
\hline Agricultural land & 572.5 & 799.1 & 39.6 & 109.1 & 104.4 & -4.3 \\
Built-up land & 12.7 & 131.2 & 933.1 & 5.6 & 8.3 & 48.2 \\
Forests & 36.4 & 30.5 & -16.2 & 22.1 & 46.5 & 110.4 \\
Domestic gardens & 848.1 & 560.9 & -33.9 & 175.6 & 149.9 & -14.6 \\
Water bodies & 53 & 21.5 & -59.4 & 9.6 & 10.4 & 8.3 \\
Mangroves and marshes & 52.9 & 32.4 & -38.8 & - & - & - \\
\hline
\end{tabular}

Table2a. Water supply requirement according to sectors and sources

\begin{tabular}{|l|l|l|l|l|l|l|}
\hline \multirow{2}{*}{ Water Resource } & \multicolumn{2}{|c|}{2001} & \multicolumn{2}{c|}{2010} & \multicolumn{2}{c|}{2020} \\
\cline { 2 - 7 } & Surface & Ground & Surface & Ground & Surface & Ground \\
\hline Domestic supply & 380,248 & 105,621 & 441,971 & 115,328 & 506,325 & 118,684 \\
Industrial supply & 158,445 & 6,970 & 181,508 & 7,129 & 198,898 & 9,465 \\
Other & 33,280 & 976 & 46,098 & 1,810 & 58,913 & 2,803 \\
\hline NRW & \multicolumn{2}{|c|}{243,956} & \multicolumn{2}{|c|}{206,138} & \multicolumn{2}{c|}{200,051} \\
\hline
\end{tabular}

Table2b. Water supply requirement according to sectors and sources

\begin{tabular}{|l|l|l|l|l|l|l|}
\hline \multirow{2}{*}{ Water Resource } & \multicolumn{2}{c|}{2001} & \multicolumn{2}{c|}{2010} & \multicolumn{2}{c|}{2020} \\
\cline { 2 - 7 } & Surface & Ground & Surface & Ground & Surface & Ground \\
\hline Domestic supply & 36,679 & 31,300 & 61,029 & 98,415 & 86,336 & 107,207 \\
Industrial supply & 5,972 & 804 & 15,157 & 1,684 & 16,690 & 1,451 \\
Other & - & - & - & - & - & - \\
\hline NRW & \multicolumn{2}{|c|}{22,928} & \multicolumn{2}{|c|}{28,068} & 18,141 \\
\hline
\end{tabular}


populations in 1999 were 5.86 and 13.05 millions respectively).

The sectoral water requirements for water supply within the two urban areas are given in Table $2 \mathrm{a}$ and Table $2 \mathrm{~b}$ for Colombo and Kandy respectively. According to the Department of Statistics, the piped water coverage by 2001 was $64 \%, 22.2 \%$ and $40 \%$ in Colombo, Gampaha and Kandy districts respectively. Individual domestic groundwater consumers in the Colombo and Kandy study areas are estimated to be using approximately 34.5 and 10 million cubic meters a year. Due to limited coverage the approximate amount of groundwater used in piped water supply schemes in the Colombo and Kandy study areas are of the study area are $6,400 \mathrm{~m}^{3} / \mathrm{d}$ and $18,100 \mathrm{~m}^{3} / \mathrm{d}$ respectively for year 2001. The total groundwater extraction including the exploitation by the individuals using shallow wells amounts to $113,567 \mathrm{~m}^{3} / \mathrm{d}$ and $32,104 \mathrm{~m}^{3} / \mathrm{d}$ respectively. The total number of recorded deep groundwater extraction wells in the Colombo, Gampaha and Kandy districts is 342,890 and 1754 , respectively.

Groundwater management; Over the past decades, the Water Resources Board (WRB), National Water Supply and Drainage Board (NWS\&DB) and the Agriculture Development Authority (ADA) are all engaged in investigations into and development of groundwater resources in Sri Lanka. In addition, a few private drilling companies and donor-funded projects have also been engaged in the investigation and development of this resource. In terms of monitoring and data collection, these organizations collect data primarily for their own use, although certain information is shared with other agencies and public. These data collections are limited only to deep wells and in most cases, it is only the drill log including the initial water levels and the initial water quality. As there are no legislative requirements available for the assessment planning or management of groundwater, none of above agencies takes responsibility of the management of the groundwater resources of the country. Because of this at present there is no continuous groundwater-related monitoring data available. This makes it difficult to predict the recharge potentials and thus control the adverse impacts from the present developments taking place in groundwater extraction areas.

In regions of vesicular laterite aquifers, some are highly productive. So they are commonly used for medium-scale piped water supply schemes. Excessive abstraction that mostly occurs in the laterites located away from the flood plain results in the lowering of the water table. When these aquifers are used excessively, the aquifers themselves are subjected to localized groundwater table depletions affecting the groundwater wells in the surrounding areas.

At present the semi-confined rock aquifers are widely exploited for industrial activities, and for water-supply schemes which are generally in high volumes. Though these extractions are continuing, according to the NWS\&DB, many of these deep hard-rock abstractions are experiencing a rapid lowering of water levels (over $40 \mathrm{~m}$ drop in Kandy region) or decreased yields or both. Some of these affected areas are shown in figure 2. In addition, personal

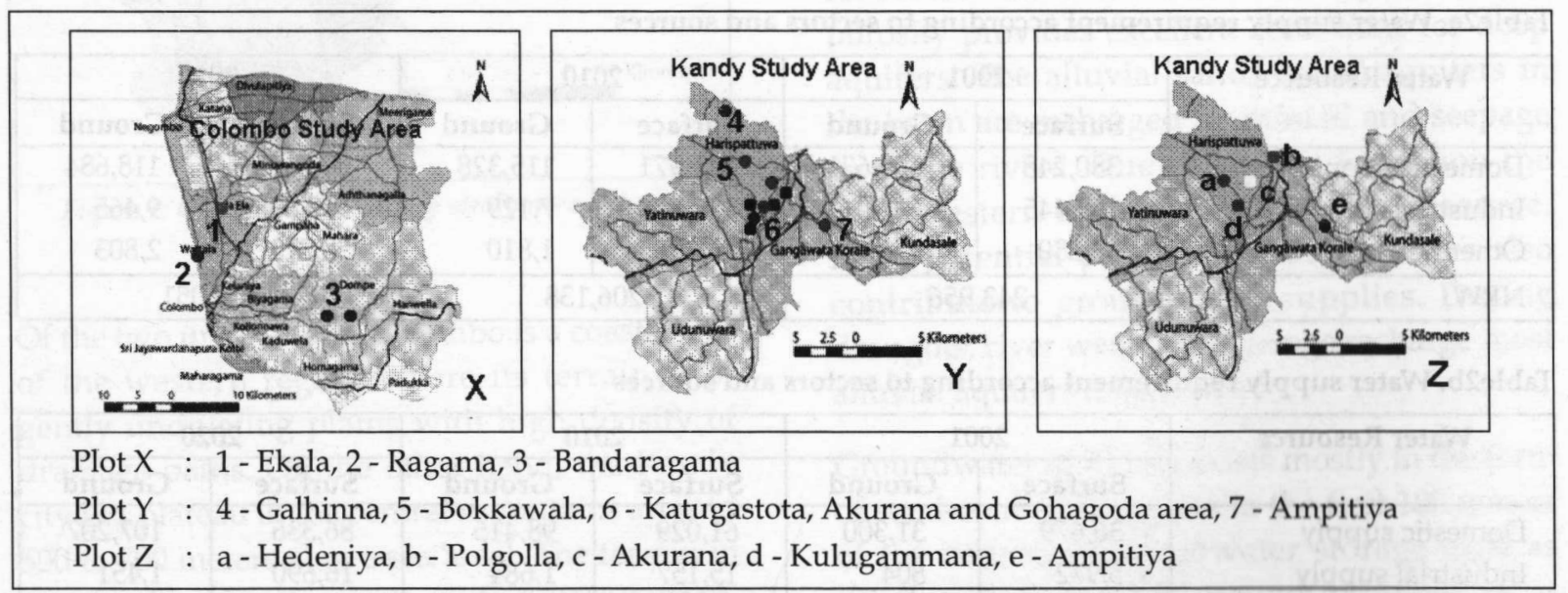

Figure 2: Some identified groundwater problem locations

(Plot X \& Y- extraction problems, Plot Z - shallow groundwater quality problems) 
communication revealed that a number of groundwater wells in the study region, especially in Kandy, have been abandoned due to groundwater depletion. Most of the surviving schemes at present have curtailed supply of few hours a week. The actual causes for these failures are largely unknown both due to the lack of information and proper instrumentation for investigations, but may most likely be due to over extractions taking place.

Both in Colombo and Kandy, there is no continuous monitoring of groundwater quality being done. Based on the quality measurements taken from many bore-hole wells constructed in Kandy during test pumping, have shown high levels of hardness, iron and nitrite. Hardness as high as $1125 \mathrm{mg} / 1$ has been recorded in these areas, with the total iron at $18 \mathrm{mg} / \mathrm{l}$, nitrites at $128 \mathrm{mg} / \mathrm{l}$ and sulphates at $500 \mathrm{mg} / 1$. In Colombo except for the high iron content in some of the locations the groundwater quality is fairly good. However, an investigation by Gunawardhana et. al., (2002) shows that many shallow wells in southern Colombo was abandoned due to odor and taste problems caused by contamination of the groundwater with partially treated industrial effluents. Also high Mn (0.92 mg/l), Ag (0.58 mg/l), Ni (0.21 $\mathrm{mg} / \mathrm{l}), \mathrm{Cr}(0.13 \mathrm{mg} / \mathrm{l}), \mathrm{Pb}(0.04 \mathrm{mg} / \mathrm{l})$ and $\mathrm{Al}$ (5.62 $\mathrm{mg} / 1$ ) concentrations were observed in these wells. Although the present level of groundwater monitoring is poor, using the available limited monitoring it was found that many shallow groundwater wells in the study areas are contaminated with coliform (figure 2).

\section{Conclusions}

The rapid increase of population that has taken place in urban areas over the recent past, caused a deterioration of both the quantity and quality of available water. The data analyzed shows the shallow groundwater is contaminated with chemical in southern Colombo and with coliform in the Kandy region. On the supply side, lowered yield and water table drop is seen as the major issues to be addressed in the groundwater management.

Based on the findings in this study, following measures are recommended as possible options to be implemented to mitigate further deterioration of the groundwater resource.
- Location specific management program ensuring sustainability of the groundwater resource.

- Vested authority for coordinating the planning and the management of groundwater.

- Encourage more research and development in sustainable groundwater management and disseminating them effectively

- Initiate programs for monitoring of quantity, quality and replenishment

- Developing suitable guidelines for sustainable exploitation of the resource and disseminating the guidelines widely.

- Establish a registration program for heavy groundwater users to track groundwater development.

- Demarkation and protection of groundwater sensitive areas.

- A program to safeguard the rights of shallow well users while protecting from contamination.

\section{Acknowledgement}

The Authors wishes to thank the Freshwater Resources Management Project of the Institute for Global Environmental Strategies (IGES) Japan for the financial and technical support provided.

\section{References}

1. "Earthtrends" (2003), Water Resources and Freshwater Ecosystems Country Profile Sri Lanka, Water Resource Institute web page: http:// earthtrends.wri.org/text/water-resources/ country-profile-167.html

2. Genawardhana W D D H, Jayaweera M W and Kasturiarachchi J C, (2002), Heavy Metal Levels in Groundwater in the Ratmalana-Moratuwa Industrial Area: A comprehensive survey carried out in 2002, Research Sessions, Department of Civil Engineering, University of Moratuwa, Sri Lanka.

3. National Water Resources Policy and Institutional Arrangements 2000, Draft Proposal, Water Resources Council and Secretariat, Government of Sri Lanka

4. Panabokke, C.R. 2003. Nature of occurrence of the regolith aquifer in the hard rock region of Sri Lanka. Symposium on use of groundwater for agriculture in Sri Lanka, AESL/PGIA Peradeniya. 
5. Ratnayake U R and Herath G B B, 2005. "Recent Changes in Water Cycle and its Effect on Natural disasters and Eco Systems of Sri Lanka", Proceedings, "Preparatory Workshop on Sri Lanka National Water Development Report - for UNWWAP", Wattala, Sri Lanka

6. WHO/UNISEF Joint Monitoring Program for water supply and sanitation (July 2004); Coverage Estimates of Improved Drinking Water. wssinfo.org 